Article

\title{
Surface Crack Detection in Precasted Slab Track in High-Speed Rail via Infrared Thermography
}

\author{
Zai-Wei Li ${ }^{1}$, Xiao-Zhou Liu ${ }^{2}$, Hong-Yao Lu ${ }^{1}$, Yue-Lei He ${ }^{1}$ and Yun-Lai Zhou ${ }^{3} * * \mathbb{C}$ \\ 1 School of Urban Rail Transportation, Shanghai University of Engineering Science, Shanghai 201620, China; \\ lzw_5220964@163.com (Z.-W.L.); lhy@sues.edu.cn (H.-Y.L.); hyldoc@163.com (Y.-L.H.) \\ 2 College of Urban Transportation and Logistics, Shenzhen Technology University, Shenzhen 518118, China; \\ liuxiaozhou@sztu.edu.cn \\ 3 State Key Laboratory for Strength and Vibration of Mechanical Structures, School of Aerospace Engineering, \\ Xi'an Jiaotong University, Xi'an 710049, China \\ * Correspondence: yunlai.zhou@xjtu.edu.cn
}

Received: 10 October 2020; Accepted: 26 October 2020; Published: 29 October 2020

check for updates

\begin{abstract}
The surface crack of ballastless track slab can seriously reduce the serviceability and durability of high-speed railway (HSR). Aiming at accurately and efficiently detecting the slab cracks, this research proposes an infrared thermography (IRT)-based method for the surface crack, which is the most serious and common crack type in track slab. A three dimensional finite element (FE) model of IRT detection of concrete slab with surface cracks is established. The relation between the width of detectable cracks and the ambient temperature can be thereby obtained by inputting the measured thermodynamic parameters in the model. Parametric study shows that with ambient temperature higher than $15^{\circ} \mathrm{C}$, cracks with a width of no less than $0.2 \mathrm{~mm}$ can be well detected. Scale model test and field test are conducted, IRT method can effectively locate the slab surface cracks with width as small as $0.14 \mathrm{~mm}$ when ambient temperature is no less than $20^{\circ} \mathrm{C}$.
\end{abstract}

Keywords: infrared thermography (IRT); high-speed railway (HSR) track slab; surface crack; finite element (FE) simulation; field test

\section{Introduction}

Longitudinally coupled prefabricated slab tracks (LCPSTs) are widely used in the new high-speed railway (HSR) lines in many countries, such as Germany, Japan, and China. In China, for instance, it accounts for about 35\% of the total length of the national HSR network. LCPST is a multi-layer structure composed by concrete track slab, cement asphalt (CA) mortar layer and concrete base. The concrete slab is prefabricated and dummy joints are adopted to prevent concrete crack and its expansion, as shown in Figure 1 [1,2]. However, the practical experience of HSR operation in various countries shows that with the increase of the service time of the rail line, the performance of the track slab deteriorates significantly, and structural defects such as cracks and deformation of track slab can inevitably appear gradually [3]. Under the combined effect of temperature, rainwater, and dynamic load of reciprocating train, these cracks can aggravate the concrete looseness and water seepage near the cracks, lead to the corrosion of the internal reinforcing bars, and significantly reduce the service durability and stability of track slab structure $[4,5]$. With the continuous increase, expansion and penetration of the cracks, the integrity of track slab can be damaged, which directly affects the dynamic response characteristics of track structure, and even becomes the main hidden danger seriously threatening the operation safety of HSR [6]. How to detect the crack of track slab timely and effectively has become an important problem to be solved in the maintenance of HSR ballastless track. 

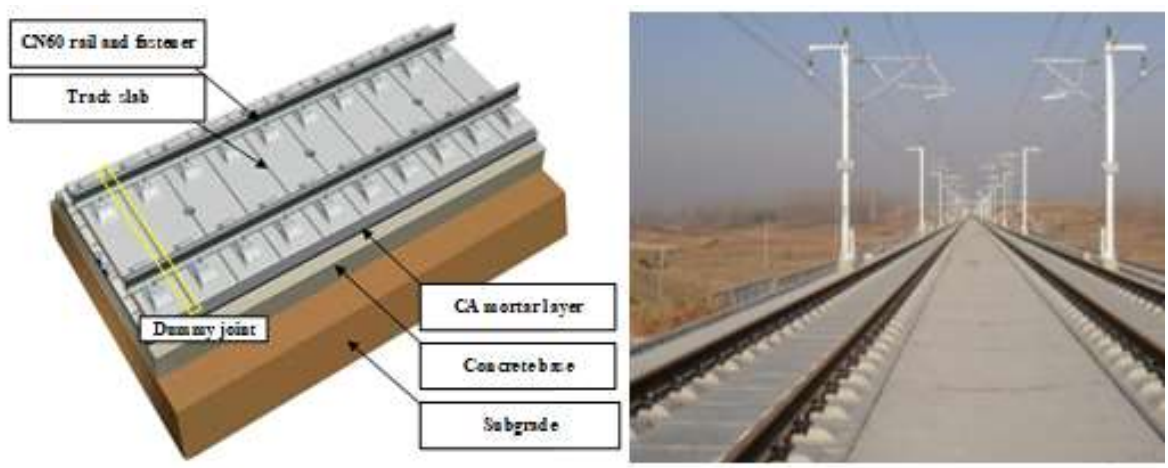

Figure 1. Longitudinally coupled prefabricated slab track (LCPST).

Most of the railway departments around the world adopt manual inspection to detect the cracks of track slabs. However, manual inspection is characterised with low efficiency and great reliance on personal experience [7]. In addition, the maintenance time of HSR lasts only 1 to $2 \mathrm{~h}$, which implicates massive employees for the track maintenance of hundreds and thousands kilometers. That can also be serious interference to route safety management [8]. To tackle this problem, extensive studies focused on the issues of track slab crack.

Considering that ballastless track slab is a typical prestressed concrete structure, many previous studies adopt the regular contactless nondestructive testing (NDT) methods for track defect detection, including impact echo testing [9-11], ultrasonic testing [12,13], ground penetrating radar [14-16], acoustic emission testing [17-19], etc. Combined with relevant mechanical theoretical calculations, track defect can be analysed qualitatively and quantitatively. However, these efforts mainly focus on track slab inter-layer defects, rather than slab surface cracks which is a critical problem for LCPSTs. Current research on slab crack is generally based on fixed-point local detection. The characteristics of the test data are relatively complex, which requires more experience. Apart from the above NDT methods, computer vision techniques with artificial intelligence methods are also adopted in track inspection $[8,20,21]$. Certainly there are also studies focused on the material scale degradation subjected to extreme condition [22-24]. However, for such a complex inspection environment as slab ballastless track structure, lighting factors and noise factors such as rails, fasteners and other components will make it very difficult to accurately identify the cracks in the track slab on site. There is no accurate model to describe the mode of crack damage. These factors become the great obstacles.

Infrared thermography (IRT), as a novel NDT method, has been more and more widely used in civil engineering. This method explores the surface infrared radiation and surface temperature field, to test surface or interior damage with thermal imaging camera [25]. Currently, IRT has been used in crack detection of building structures [26-28] and bridges [29-31], but it is relatively new in track crack inspection [32]. Thermography is suitable for crack detection with width as small as $0.5 \mathrm{~mm}$ with flash thermography [27].

This research, based on the field investigation into the characteristics of surface crack on track slab, proposes an IRT-based crack detection method for LCPST, with the combination of theoretical analysis and experiment. The remainder of this paper is organised as follows: the distribution of ballastless track crack is discussed in Section 2; the theory of thermography and the calculation of track slab thermodynamics is presented in Section 3; finite element (FE) analysis of concrete track slab is given in Section 4, followed by laboratory test and the field test results, as presented in Section 5; the last section gives the brief conclusions.

\section{Field Investigation of Slab Crack}

The actual defect characteristics are fundamental to the application of the IRT-based detection method for slab tracks. However, there is little study dedicated to carrying out field investigation into the cracks on the in-service track slabs. With the assistance of China Railway Shanghai Group, 
this research conducts field investigation on a $158 \mathrm{~km}$-long HSR line in East China. This line was built in 2010 with CRTS-II slab track. The operation speed of the line is $300 \mathrm{~km} / \mathrm{h}$ and the main types of foundation are subgrade and simply supported beam bridge.

Figure 2 shows the typical slab cracks found by field investigation. The surface cracks can occur at dummy joints and other locations on the slabs. The cracks at dummy joints are mainly short cracks perpendicular to the side of the dummy joints and some through cracks expand through the surface and from side to bottom. The cracks at other locations on the slab are mainly short splayed diagonal cracks along the sleeper's direction and transverse through cracks along the side of the sleepers. When the tensile stress of the track slab is greater than its tensile strength, the crack will occur at the weak location. Meanwhile, under the impact of periodic temperature load, the expansion and deformation of the track slab can happen continuously, which leads to the expansion of the crack along the transverse direction until it develops into a through crack.

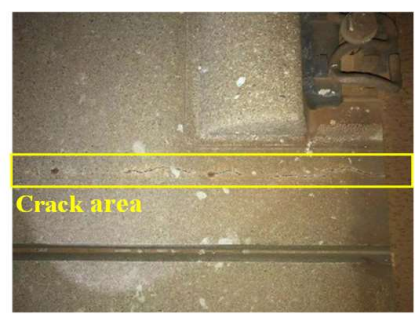

(a)

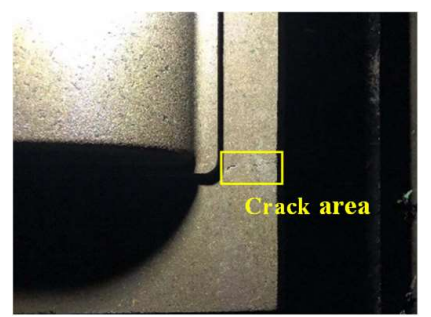

(b)

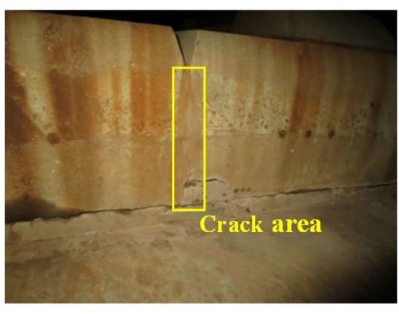

(c)

Figure 2. Track surface crack in the field: (a) Surface through crack; (b) Crack at sleeper; (c) Crack at dummy joints.

Table 1 lists the statistical analysis results of the field investigation. A total of 73 slab cracks are identified. Among them, the proportions of cracks at dummy joints and other locations in bridge section are $52.5 \%$ and $47.5 \%$, respectively, while the proportions in subgrade section are $51.6 \%$ and $48.4 \%$, respectively. In both bridge section and subgrade section, the average values of width and length of the cracks at dummy joints are slightly larger than those of cracks at other locations, which is consistent with the design theory of ballastless track [33]. A total of 11 through cracks are found in subgrade and bridge sections, and the average width of through cracks is significantly larger than that of non-through cracks, with the maximum width of $0.82 \mathrm{~mm}$. Compared with the non-through cracks whose average width is only about $0.13 \mathrm{~mm}$, the damage state of through cracks is more serious. Referring to the management rule for China HSR [34], when surface crack width is larger than $0.2 \mathrm{~mm}$, immediate repair is required.

Table 1. Statistics of the investigated track cracks.

\begin{tabular}{lccccccccc}
\hline \multirow{2}{*}{ Section } & \multirow{2}{*}{ Location } & \multirow{2}{*}{ Type } & \multirow{2}{*}{ Count } & \multicolumn{3}{c}{ Length/cm } & \multicolumn{3}{c}{ Width/mm } \\
\cline { 6 - 9 } & & & & Max & Min & Avg & Max & Min & Avg \\
\hline \multirow{3}{*}{ Bridge } & \multirow{3}{*}{ Dummy joint } & Through cracks & 2 & $/$ & $/$ & $/$ & 0.36 & 0.14 & 0.27 \\
& & Others & 19 & 16 & 12.11 & 15.26 & 0.19 & 0.1 & 0.16 \\
& \multirow{2}{*}{ Others } & Through cracks & 3 & $/$ & $/$ & $/$ & 0.32 & 0.11 & 0.24 \\
& & Others & 16 & 18.8 & 2.89 & 14.94 & 0.13 & 0.02 & 0.10 \\
\hline \multirow{6}{*}{ Roadbed } & \multirow{3}{*}{ Dummy joint } & Through cracks & 2 & $/$ & $/$ & $/$ & 0.28 & 0.12 & 0.23 \\
& & Others & 15 & 14.22 & 4 & 11.51 & 0.19 & 0.08 & 0.15 \\
& \multirow{2}{*}{ Others } & Through cracks & 4 & $/$ & $/$ & $/$ & 0.82 & 0.09 & 0.29 \\
& & Others & 12 & 15.33 & 2.56 & 9 & 0.16 & 0.01 & 0.11 \\
\hline
\end{tabular}

\section{IRT Testing for Slab Crack Detection}

Any object with a temperature higher than absolute zero will continuously radiate infrared light to the external environment. Because the surface temperature and thermal physical parameters of the 
objects are different, the ability of the objects to radiate infrared light to the external environment is also different. The higher the temperature of the object, the stronger the ability of infrared radiation to the external environment. IRT, as a novel NDT technique, can detect the different intensity infrared thermal waves emitted by object surface and convert them into infrared thermal images with different colours [25]. For track slab, when a crack appears on its surface, a significant difference between the thermal conductivity of air medium in cracks and that of concrete materials will generate. When the heat flow enters the crack, the heat will accumulate in the crack area; when the heat flow exits, the air medium in cracks slows down the heat dissipation, resulting in the temperature difference of crack area and non-crack area, which generates temperature gradient field (see Figure 3). With IRT, we can detect the surface crack of track slab by collecting such temperature difference.

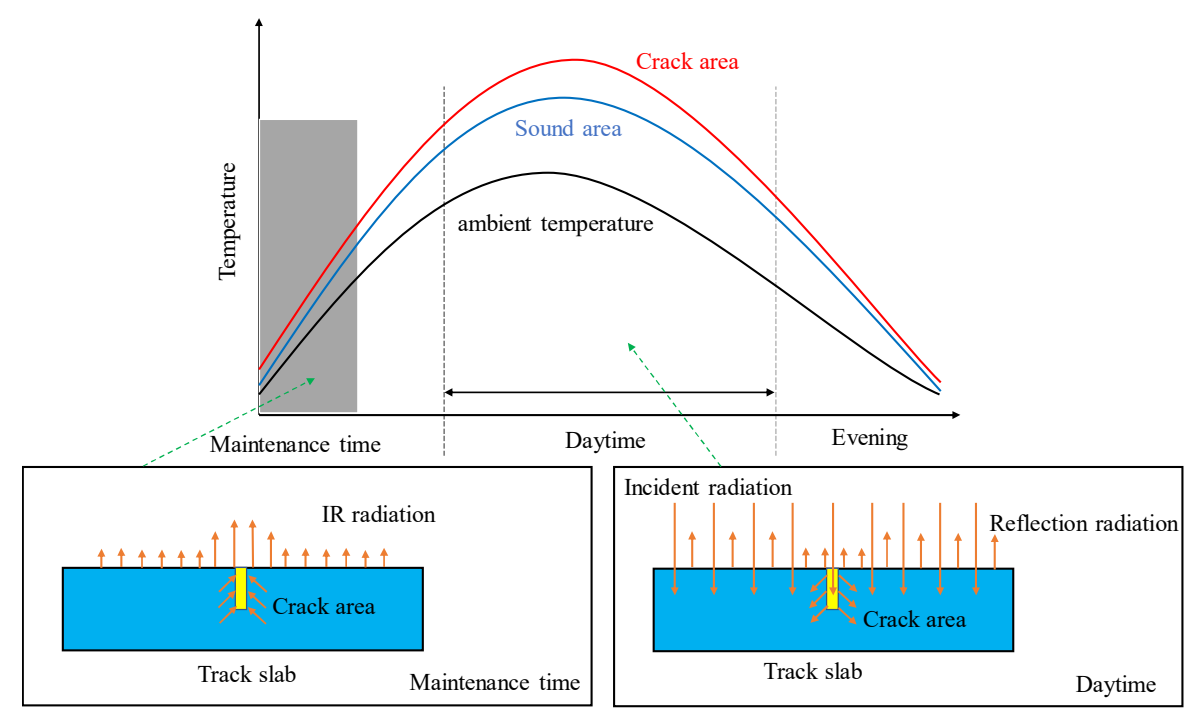

Figure 3. Mechanism of infrared imagery technology.

For the concrete track slab, in the actual heat transfer process, due to the uneven distribution of the internal temperature field, the following assumptions are made for the convenience of presenting the principle of heat sensor detection:

A. Due to the low thermal conductivity of concrete, it is considered that there is no coupling between temperature and structural deformation.

B. Track slab is assumed to be homogeneous and isotropic.

C. The thermal parameters of track slab materials are all constant and do not change with the change of temperature.

The heat transfer process inside an object can be expressed by the following formula [25] as

$$
\frac{\partial}{\partial x}\left(\lambda \frac{\partial T}{\partial x}\right)+\frac{\partial}{\partial y}\left(\lambda \frac{\partial T}{\partial y}\right)+\frac{\partial}{\partial z}\left(\lambda \frac{\partial T}{\partial z}\right)=\rho c \frac{\partial T}{\partial t}
$$

where $\lambda$ is the conductivity $\left(\mathrm{W} \cdot \mathrm{m}^{-1} \cdot{ }^{\circ} \mathrm{C}^{-1}\right), \rho$ is the density $\left(\mathrm{kg} \cdot \mathrm{m}^{-3}\right), \mathrm{c}$ is the specific heat capacity $\left(\mathrm{J} \cdot \mathrm{kg}^{-1} \cdot{ }^{\circ} \mathrm{C}^{-1}\right)$, $\mathrm{t}$ is time $(\mathrm{s}), \mathrm{T}$ is temperature inside the slab $(\mathrm{C})$, and $\mathrm{x}, \mathrm{y}$, and $\mathrm{z}$ are axis directions.

Since the window time HSR maintenance is always at night, the temperature field of track slab is mainly affected by the ambient temperature because of the continuous radiation and convection heat exchange between track slab and external environment. As a continuous concrete structure, the vertical 
dimension of track slab is far smaller than its transverse and longitudinal dimensions, so it can be treated as an infinite flat wall structure, and Equation (1) can be rewritten as

$$
\frac{\partial}{\partial x}\left(\lambda \frac{\partial T}{\partial x}\right)=\rho c \frac{\partial T}{\partial t}
$$

To solve Equation (2), boundary conditions of temperature and heat transfer is established as

$$
\text { s.t. } \begin{cases}\mathrm{T}=\mathrm{T}_{0} & , \mathrm{t}=0 \\ \partial \mathrm{T} / \partial \mathrm{x}=0 & , \mathrm{x}=0 \\ -\lambda \cdot \partial \mathrm{T} / \partial \mathrm{x}=\mathrm{h}\left(\mathrm{T}-\mathrm{T}_{\mathrm{a}}\right) & , \mathrm{x}=\mathrm{d}\end{cases}
$$

where $\mathrm{T}$ is slab internal temperature $\left({ }^{\circ} \mathrm{C}\right), \lambda$ is track slab conductivity $\left(\mathrm{W} /\left(\mathrm{m} \cdot{ }^{\circ} \mathrm{C}\right)\right), \rho$ is slab density $\left(\mathrm{kg} / \mathrm{m}^{3}\right)$, c is specific heat $\left(\mathrm{J} /\left(\mathrm{kg} \cdot{ }^{\circ} \mathrm{C}\right)\right), \mathrm{x}$ is axis for thickness, $\mathrm{d}$ is track thickness $(\mathrm{m}), \mathrm{T}_{0}$ is the initial temperature $\left({ }^{\circ} \mathrm{C}\right), \mathrm{T}_{\mathrm{a}}$ is ambient temperature $\left({ }^{\circ} \mathrm{C}\right), \mathrm{h}$ is the integrated heat transfer coefficient (i.e., the sum of radiative coefficient $h_{r}$ and convective heat transfer coefficient $\left.h_{w}\right)\left(W /\left(m^{2} .{ }^{\circ} \mathrm{C}\right)\right.$ ).

For dimensionless representation, let

$$
\left\{\begin{array}{c}
\theta=T-T_{a} \\
F=\theta / \theta_{0} \\
X=x / d
\end{array}\right.
$$

Substitute Equation (4) to Equations (2) and (3) yield

$$
\begin{gathered}
\partial \mathrm{F} / \partial\left(\mathrm{at} / \mathrm{d}^{2}\right)=\partial^{2} \mathrm{~F} / \partial \mathrm{X}^{2} \\
\text { s.t. } \begin{cases}\mathrm{F}=\mathrm{F}_{0}=1 & , \mathrm{t}=0 \\
\partial \mathrm{F} / \partial \mathrm{X}=0 & , \mathrm{X}=0 \\
\partial \mathrm{F} / \partial \mathrm{X}=\mathrm{hd} \cdot \mathrm{F} / \lambda & , \mathrm{X}=1\end{cases}
\end{gathered}
$$

where $\mathrm{a}$ is diffusivity coefficient (i.e., $\mathrm{a}=\lambda / \rho \mathrm{c}$ ).

Use Fourier number $F_{o}$ to represent the time of unsteady heat conduction, and Bivot $B_{i}$ for the ratio of heat resistance between interior and surface of slab, dimensionless temperature can be given by

$$
\left\{\begin{array}{c}
\mathrm{F}_{\mathrm{o}}=a t / \mathrm{d}^{2} \\
\mathrm{~B}_{\mathrm{i}}=h d / \lambda \\
\mathrm{F}=\mathrm{g}\left(\mathrm{F}_{\mathrm{o}}, \mathrm{B}_{\mathrm{i}}, \mathrm{X}\right)
\end{array}\right.
$$

With slab surface crack, temperature difference between crack and non-crack area is given by

$$
\Delta \mathrm{T}=\mathrm{T}_{1}-\mathrm{T}_{\mathrm{h}}
$$

where $T_{1}$ and $T_{h}$ refer to crack and non-crack temperature.

Combined with the influence of crack length (l) and width (w), the following equation is established

$$
\Delta \mathrm{T}=\mathrm{g}\left(\theta_{0}, \mathrm{t}, \mathrm{a}, \mathrm{d}, \lambda, \mathrm{h}, \mathrm{l}, \mathrm{w}\right)
$$

According to $\pi$ theorem and dimension harmony theorem, we select four basic parameters (i.e., $\Delta \mathrm{T}, \mathrm{t}, \lambda$, and $\mathrm{d}$ ), so that the dimensionless equation is given by

$$
\mathrm{F}\left(\frac{\theta_{0}}{\Delta \mathrm{T}}, \frac{\text { at }}{\mathrm{d}^{2}}, \frac{\mathrm{hd}}{\lambda}, \frac{1}{\mathrm{~d}}, \frac{\mathrm{w}}{\mathrm{d}}\right)=0
$$


So $\Delta \mathrm{T}$ can be expressed as

$$
\Delta \mathrm{T}=\mathrm{f}\left(\frac{\text { at }}{\mathrm{d}^{2}}, \frac{\mathrm{hd}}{\lambda}, \frac{\mathrm{l}}{\mathrm{d}}, \frac{\mathrm{w}}{\mathrm{d}}\right) \times \theta_{0}=\Theta \times \mathrm{C} \times \mathrm{R}
$$

where $\Theta$ is temperature coefficient mainly determined by ambient temperature, $C$ is scale coefficient which is mainly determined by crack width, and $\mathrm{R}$ is the constant thermal coefficient.

Solving the temperature difference in Equation (10) is fundamental to the application of IRT in slab surface cracks detection. To determine the mapping relationship between the ambient temperature, crack width and temperature difference. Because of the irregular shape of the cracks on the surface of the slab and the randomness of the ambient temperature, it is impossible to express them with explicit analytical formula, which leads to the inaccuracy of the analytical solution of the temperature field.

\section{Finite Element Analysis}

\subsection{Modeling}

To effectively detect track slab cracks by IRT, parameters such as resolution, detection window length of the camera, ambient temperature, etc. need to be set. However, the field test of such parameters are very expensive and time-consuming [35]. Therefore, as an efficient and economic way, the FE method is widely used in the optimal design of IRT test parameters $[35,36]$.

Based on the actual slab scale, a three-dimensional FE model of IRT detection of track slab with surface through cracks is established, in which Solid 70 element is used to simulate track slab, sleepers, CA mortar layer, and concrete base. The slab is $20 \mathrm{~cm}$ thick, $6.45 \mathrm{~m}$ long, and $2.55 \mathrm{~m}$ wide, supported by 10 sleepers $(0.8 \mathrm{~m} \times 0.3 \mathrm{~m} \times 0.07 \mathrm{~m})$, with V-shape dummy joints equally spaced between each sleeper at $0.65 \mathrm{~m}$ interval. The size of CA mortar layer and concrete base are $6.45 \mathrm{~m} \times 2.55 \mathrm{~m} \times 0.03 \mathrm{~m}$ and $6.45 \mathrm{~m} \times 2.95 \mathrm{~m} \times 0.3 \mathrm{~m}$, respectively. Bonding treatment is adopted between layers to ensure connection. According to the investigation results in Table 1, through crack is set at the 5th sleeper. With Boolean operation, the actual irregular cracks are simplified as regular cracks with rectangular cross-section, and mesh refinement is adopted for crack area, as shown in Figure 4. The main calculating parameters are summarised in Table 2.

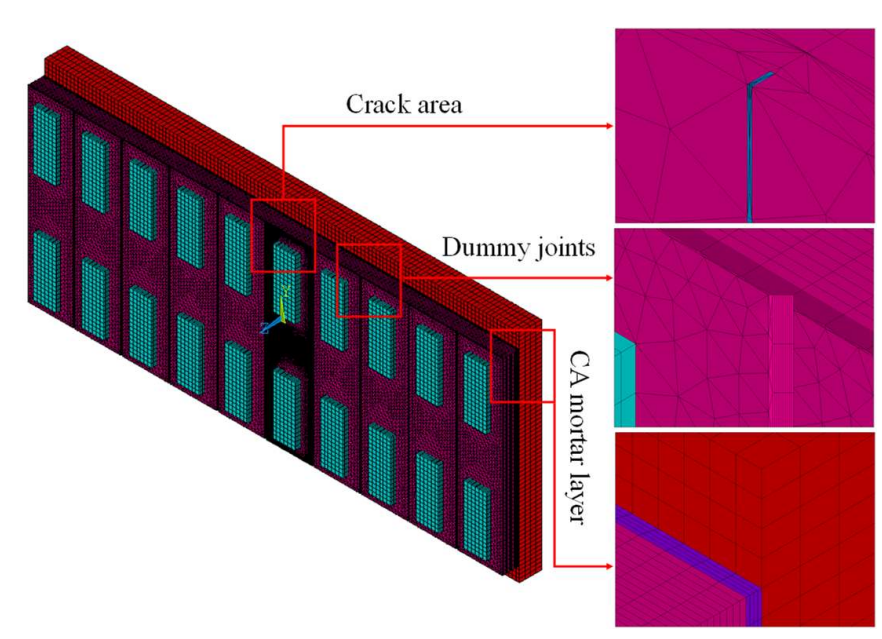

Figure 4. Three-dimension model for infrared thermography (IRT) of concrete track slab. 
Table 2. The main parameters of track modeling.

\begin{tabular}{lcccc}
\hline \multicolumn{1}{c}{ Parameters } & Slab & Sleeper & CA Mortar Layer & Concrete Base \\
\hline Specific heat $\left(\mathrm{J} \cdot \mathrm{kg}^{-1} \cdot{ }^{\circ} \mathrm{C}^{-1}\right)$ & 925 & 925 & 1350 & 925 \\
Density $\left(\mathrm{kg} \cdot \mathrm{m}^{-3}\right)$ & 2500 & 2500 & 1800 & 2300 \\
Conductivity $\left(\mathrm{W} \cdot \mathrm{m}^{-1} \cdot{ }^{\circ} \mathrm{C}^{-1}\right)$ & 3.23 & 3.23 & 0.261 & 3.23 \\
\hline
\end{tabular}

\subsection{Setting of Thermal Parameters}

From Equation (10), the initial slab temperature field and environmental meteorological parameters (solar radiation, ambient temperature and wind speed) need to be input in the simulation process. Based on the field investigation [37], thermal parameters (i.e., slab temperature) along the investigated line is collected at slab depth $0 \mathrm{~mm}, 100 \mathrm{~mm}$, and $200 \mathrm{~mm}$ with sampling interval of $30 \mathrm{~min}$ for an entire year.

During the maintenance time of HSR line (i.e., 0:00 am-3:00 am), the ambient temperature range is between -3.6 and $28.3^{\circ} \mathrm{C}$, and it changes periodically with the seasons. With recognition of this, the ambient temperatures in simulation is set as $-5,0,5,10,15,20,25$, and $30^{\circ} \mathrm{C}$. Because the initial temperature field of the track slab is not evenly distributed and presents strong time-varying features, it is more suitable to use the measured average temperature of the track slab during the maintenance time as the initial temperature field. This is reasonable because there is no solar radiation effect, and the temperature difference between the track slab and the external environment is relatively small during this period.

Under the actual conditions, complex heat transfer process, including heat conduction, heat radiation, and heat convection can occur between the track slab and external environment. To simplify the model, all the heat effects generated by radiation heat transfer including solar radiation are considered to be converted into convective heat flow density, which is applied to the upper surface of the model as the boundary condition, and the side and bottom surfaces are assumed to be adiabatic. According to the management rules for Chinese HSR [34], crack width is set to be $0.1 \mathrm{~mm}, 0.2 \mathrm{~mm}$, and $0.3 \mathrm{~mm}$ for parametric analysis.

\subsection{Model Validation}

Because the detection model established by the FE method is essentially a heat transfer model, this paper uses the measured data and the simulation results for comparative analysis to verify the model. The meteorological parameters and the initial temperature field parameters of the track slab, as listed in Table 3, are input into the model for calculation. Figure 5 shows the comparison of the actual measurement and simulation results of the internal temperature field of the track slab.

Table 3. Meteorological parameters and the initial temperature field parameters.

\begin{tabular}{ccc}
\hline \multirow{2}{*}{ Meteorological Parameters } & Max solar irradiation $\left(\mathrm{w} / \mathrm{m}^{2}\right)$ & 1136 \\
\cline { 2 - 3 } & Max wind speed $(\mathrm{m} / \mathrm{s})$ & 1.32 \\
\hline \multirow{3}{*}{ Meteorological Parameters } & Depth $/ 0 \mathrm{~mm}\left({ }^{\circ} \mathrm{C}\right)$ & 32.49 \\
\cline { 2 - 3 } & Depth $/ 100 \mathrm{~mm}\left({ }^{\circ} \mathrm{C}\right)$ & 34.77 \\
\cline { 2 - 3 } & Depth $/ 200 \mathrm{~mm}\left({ }^{\circ} \mathrm{C}\right)$ & 35.49 \\
\hline
\end{tabular}




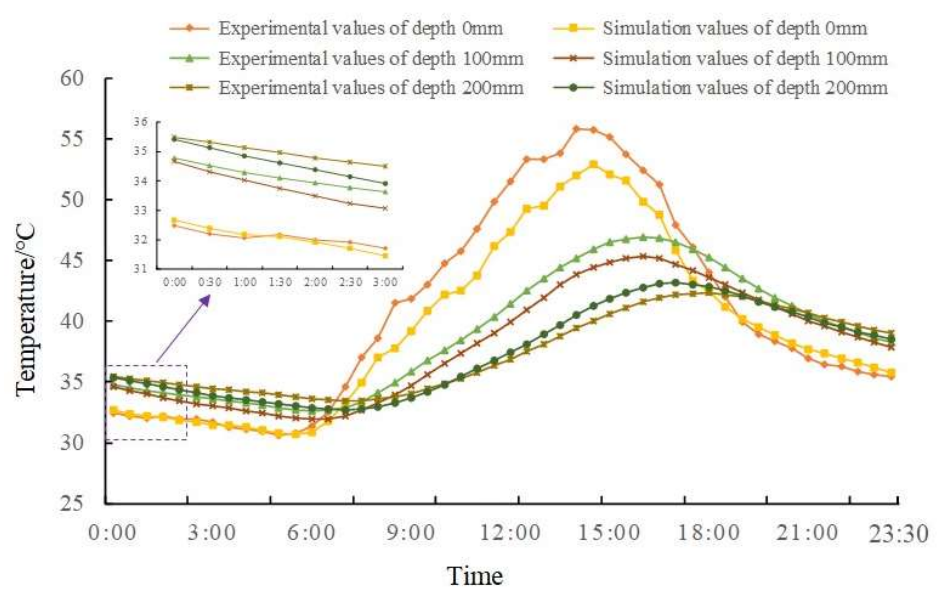

Figure 5. Comparison between the actual and simulated temperatures at varying slab depth.

From Figure 5 that there is an error between the measured and the simulated value, especially at the slab surface $(0 \mathrm{~mm})$, and the maximum difference is $4.14{ }^{\circ} \mathrm{C}$. This is due to the simplification of the boundary conditions in the FE model, in which the thermal effect caused by the direct solar radiation on the slab surface is ignored. During the period of window time for maintenance, the overall difference between the measured value and the calculated value in different depths is small, among which, the maximum difference between the two is only $0.25{ }^{\circ} \mathrm{C}$ on the slab surface and $0.58{ }^{\circ} \mathrm{C}$ at the depth of $200 \mathrm{~mm}$, the boundary between track slab and mortar layer. The explanation for the difference at $200 \mathrm{~mm}$ is that the detection model simplifies the actual three-dimensional heat conduction process into one-dimensional and that the conductivity is different between slab and CA mortar layer.

\subsection{Result Analysis}

The ambient temperatures (8 conditions) and crack widths ( 3 conditions), as mentioned in Section 4.2, are considered, and the results under 24 conditions are shown in Figure 6.

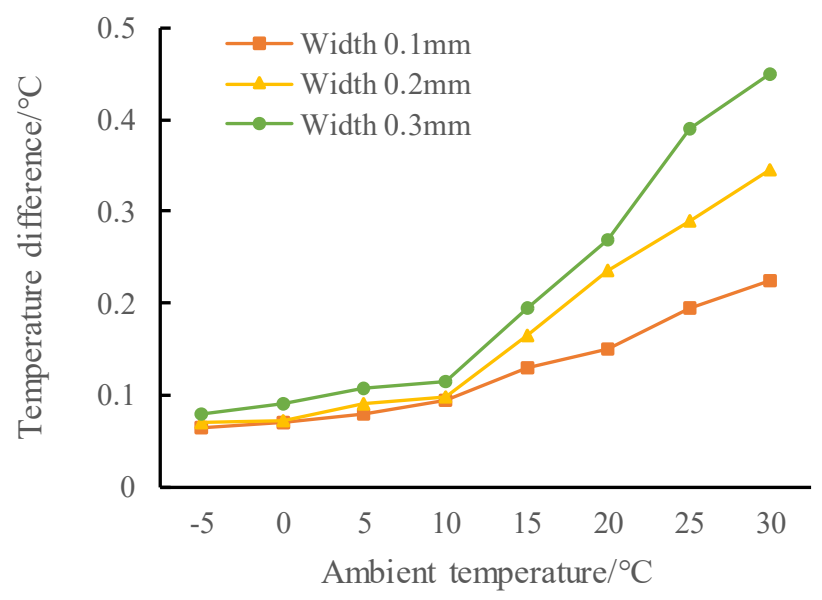

Figure 6. Crack-area temperature difference with varying crack width and ambient temperature.

As ambient temperature and crack width increases, the temperature difference between crack and non-crack area shows a growing trend; the wider the crack width is, the greater the increase of the temperature difference will be. The larger the crack width is, the more air medium is filled in the crack. Under the influence of different thermal conductivity, the temperature effect of concrete and air medium is more obvious, and the temperature difference between crack area and non crack area is more prominent. When the ambient temperature is lower than $10{ }^{\circ} \mathrm{C}$, due to the low thermal conductivity of the concrete, the overall temperature of the track slab is low, and the heat conduction 
effect between the crack area and the non crack area is slow. Even if the ambient temperature rises, the change of the temperature difference is not obvious, which is below $0.1{ }^{\circ} \mathrm{C}$, and the temperature rise is relatively gentle, so in this range crack detection can be difficult and inefficient. When the ambient temperature is between 10 and $15^{\circ} \mathrm{C}$, through crack with width of no less than $0.2 \mathrm{~mm}$ can be detected. When the ambient temperature is higher than $15^{\circ} \mathrm{C}$, the temperature difference begins to rise obviously with the increase of temperature. At $30^{\circ} \mathrm{C}$, the temperature difference of $0.3 \mathrm{~mm}$ and $0.1 \mathrm{~mm}$ cracks reaches $0.45^{\circ} \mathrm{C}$ and $0.23^{\circ} \mathrm{C}$, respectively, which means the performance of detection would be enhanced.

Taking crack with $0.2 \mathrm{~mm}$ width as an example, Figure 7 shows the colour map of through crack under different temperatures. As ambient temperature increases, the temperature of the crack edge increases, and it spreads to the non crack area, resulting in a larger zone of detectable temperature area. Besides, under the influence of sleeper's conductivity, the temperature difference zone along the crack direction becomes unstable on the side of the sleepers, while on the other side it is uniform.

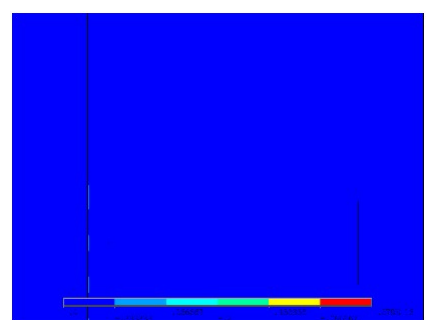

(a) $-5{ }^{\circ} \mathrm{C}$

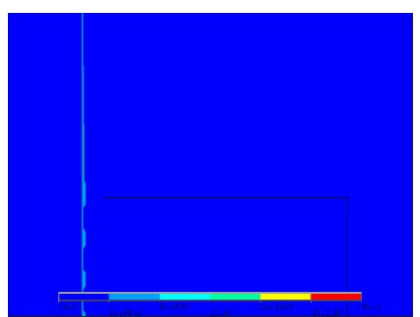

(d) $10^{\circ} \mathrm{C}$

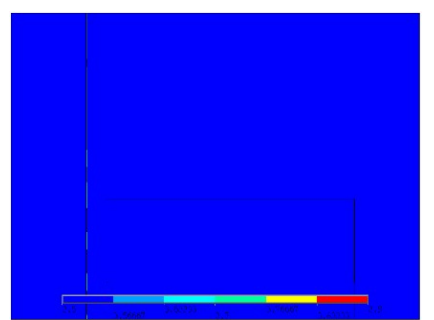

(b) $0{ }^{\circ} \mathrm{C}$

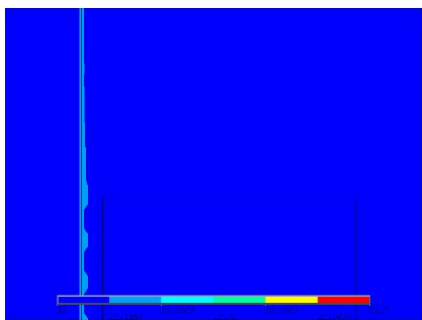

(e) $15^{\circ} \mathrm{C}$

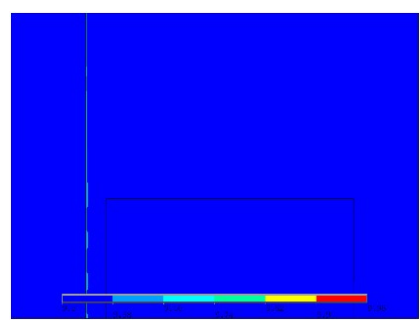

(c) $5{ }^{\circ} \mathrm{C}$

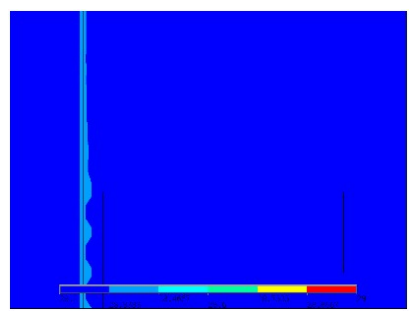

(f) $20^{\circ} \mathrm{C}$

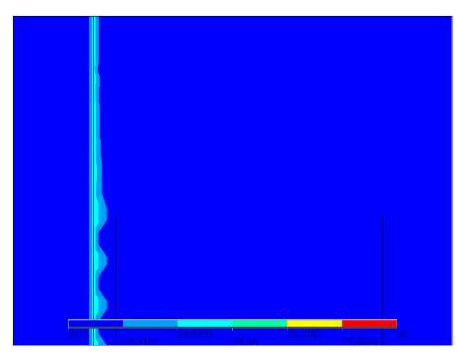

(g) $25^{\circ} \mathrm{C}$

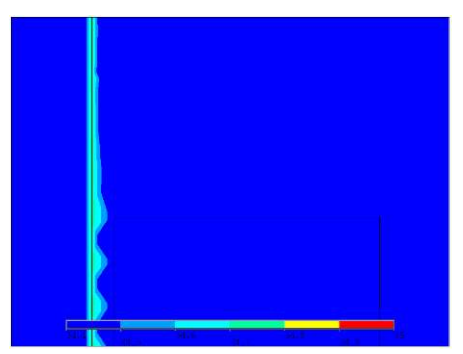

(h) $30^{\circ} \mathrm{C}$

Figure 7. Temperature colour map for through crack with $0.2 \mathrm{~mm}$ width under different ambient temperatures.

To sum up, when the ambient temperature is more than $15^{\circ} \mathrm{C}$, the through cracks with a width of more than $0.2 \mathrm{~mm}$ can be detected.

\section{Lab and Field Experiment}

\subsection{Laboratory Test}

To further determine the key parameters needed for IRT-based crack detection, samples with 1:5 scale are made in the laboratory for analysis. This is based on the similarity theory [38,39], 
which only needs to meet the conditions that the geometric size of track slab and crack is proportional, the number of Bivot is equal and the Fourier number is equal. The model size is $1290 \mathrm{~mm}(\mathrm{~L}) \times 510 \mathrm{~mm}(\mathrm{~W}) \times 200 \mathrm{~mm}(\mathrm{H})$, in which the size of the sleeper is $100 \mathrm{~mm}(\mathrm{~L}) \times 60 \mathrm{~mm}$ $(\mathrm{W}) \times 20 \mathrm{~mm}(\mathrm{H})$, and the dummy joint size is $1290 \mathrm{~mm}(\mathrm{~L}) \times 14 \mathrm{~mm}(\mathrm{~W}) \times 8 \mathrm{~mm}(\mathrm{~d})$. The model material is determined according to the China railway design code [33]. The design strength grade of concrete is $\mathrm{C} 55$ and the cement is P.O42.5 ordinary Portland cement. The fine aggregate is natural river sand and the coarse aggregate composes of $80 \%$ natural gravel with diameter of 10-20 mm and $20 \%$ natural gravel with the diameter of $5-10 \mathrm{~mm}$. The additive is hydroxy-acid water reducing agent, the admixture is fly ash, and the production water is ordinary tap water. An artificial through crack with a maximum width of $0.22 \mathrm{~mm}$ is prefabricated on the surface of the track slab. The test model is shown in Figure 8.

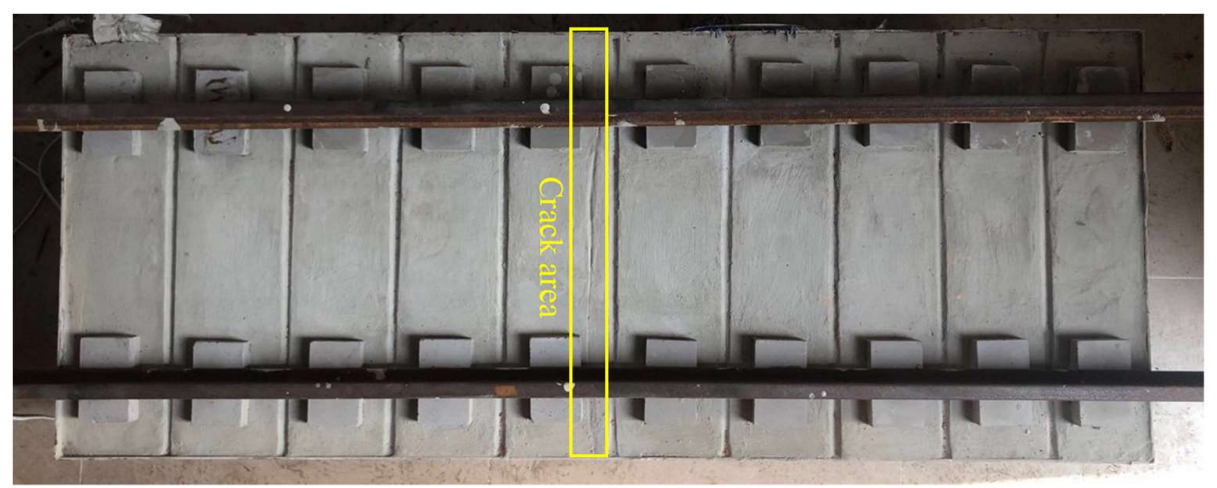

Figure 8. Scaled down sample of railway track.

To ensure that the thermal imager has the same focal length and viewing angle during shooting, a metal bracket with height of $75 \mathrm{~cm}$ is fixed at the crack area, and the width of the upper structure of the metal bracket is suitable for the outer diameter of the lens of the thermal imager, with a length of $50 \mathrm{~cm}$, to ensure that the thermal imager can cover the whole crack area during shooting. The thermal imager is inverted on the metal bracket, and the standard lens is used. The shooting range is about $6 / 10$ of the surface area of the test model, the measurement temperature range is set to $15-35{ }^{\circ} \mathrm{C}$, the focusing mode is set as auto focusing, and the thermal image display mode is set to rainbow mode for real-time storage.

The type of infrared camera is TIX620 by Fluke (Figure 9) with a heat sensitivity of $0.04{ }^{\circ} \mathrm{C}$, spectral range of 7.5-14 $\mu \mathrm{m}$, temperature measurement range of $-40-600^{\circ} \mathrm{C}$, and display resolution of $1280 \times 800$. Generally, IRT can be passive and active. Passive detection relies on an external heat source while active detection relies on the ambient temperature [29]. To simulate the actual detection environment on HSR, this study uses the passive detection to carry out experiments. First, the test model is placed in an outdoor open space exposed to sunlight to simulate the heat transfer at daytime. The model is fully excited by active heat to ensure that the surface temperature field of the model produces a certain temperature gradient. During the test, the outdoor ambient temperature is $20.2{ }^{\circ} \mathrm{C}$, the maximum solar radiation is $533 \mathrm{w} / \mathrm{m}^{2}$, and the average wind speed is $0.12 \mathrm{M} / \mathrm{s}$. Two hours later, the model is moved indoor to simulate the passive surface crack detection under the condition of no heat radiation at night, as shown in Figure 9. 


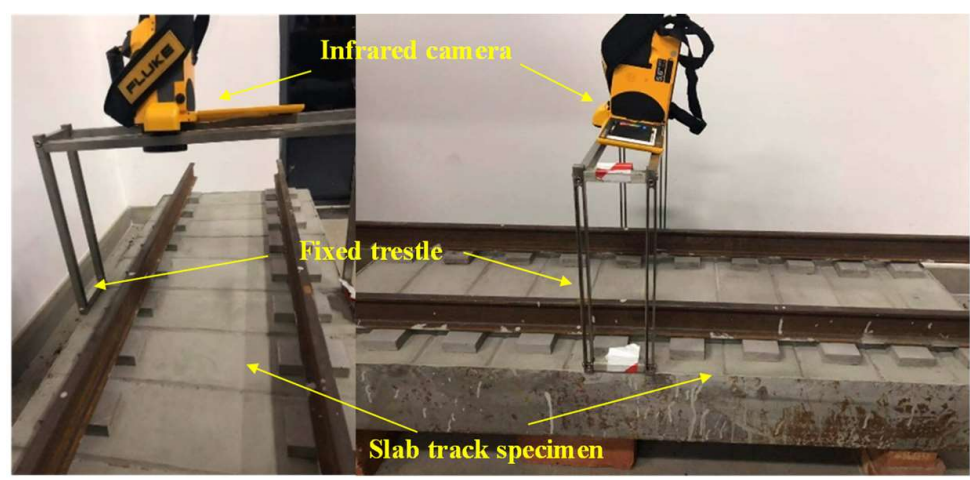

Figure 9. Infrared camera installed on the lab model.

The test results are shown in Figure 10. The temperature field on the surface of the track slab presents an obvious non-uniform distribution among different structural components. The temperature field of surface crack area and non crack area is relatively uniform in their respective areas, but there are also some local hot spots and block areas. The heat transfer process of the track plate satisfies the three-dimensional heat transfer condition and the conduction rate is quite different under the actual conditions, and it is also affected by certain environmental noise and boundary convection. In the thermal image, heat concentrates along the crack direction, and expands to the surround areas, making the crack edge fuzzy. Correspondingly, on the thermography of the crack area (right panel figure), it also presents obvious fluctuation of the amplitude. The crack area shows discontinuous pattern with much more heat at the upper part while the lower part is similar to other areas. The actual size of the upper crack is larger than the design size, so that the temperature effect is strengthened, while the width of the lower crack is small, and the thermal effect is not obvious. Besides, in the heat transfer process, the lower crack is affected by local environment and concrete boundary, so that the heat balance speed is faster. The actual temperature difference in Figure 10 is far less than that in Figure 7, the result of FE simulation. To realise effective detection of track slab cracks under the complex effect of lab radiation and convection, the ambient temperature is not recommended to be less than $20^{\circ} \mathrm{C}$.
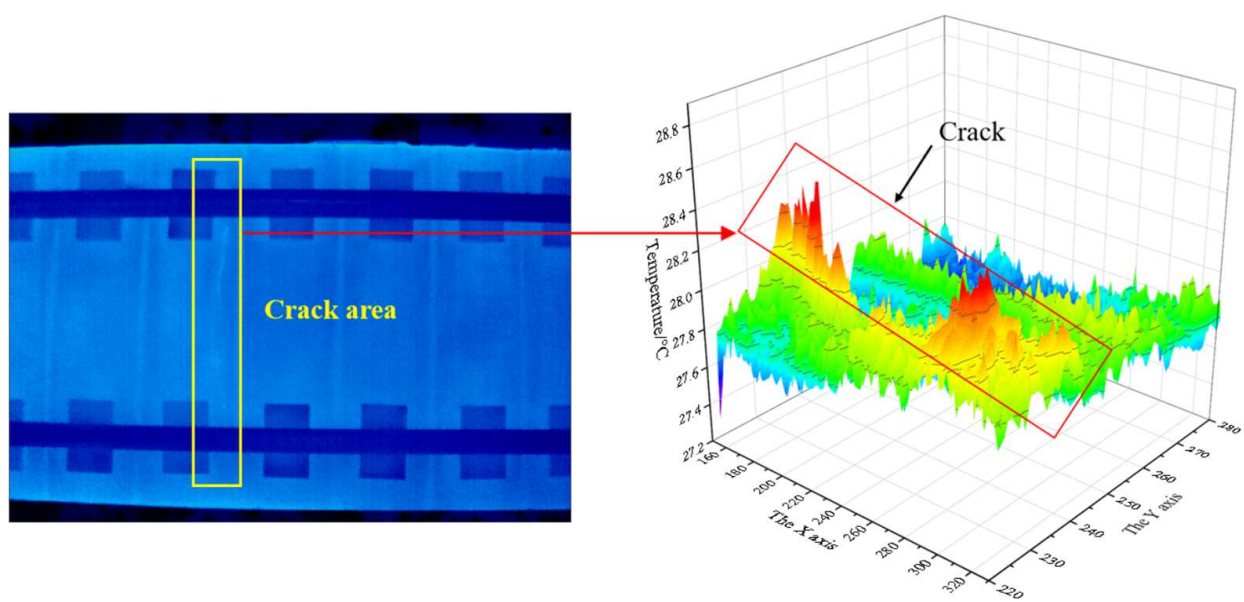

Figure 10. Thermography of lab experiment.

To extract the feature of the surface crack area in Figure 10, we use the temperature field isotherm method [40] and the result is shown in Figure 11. At the surface crack area and the dummy joint area, there is a long high temperature envelope area in the isotherm diagram. The isotherm trend of the same dummy joint is roughly the same, only different in amplitude and background noise. By using the relative position relation and calculating the crack area according to the isotherm diagram, 
we can identify that the maximum crack width is $0.32 \mathrm{~mm}$ and the minimum crack width is $0.1 \mathrm{~mm}$. Through the multi-point sum calculation, we can obtain the area value of $61.15 \mathrm{~mm}^{2}$, compared to the actual value of $66 \mathrm{~mm}^{2}$, with error of $7.35 \%$. The performance is validated by applying IRT to crack detection with respect to crack area and width.

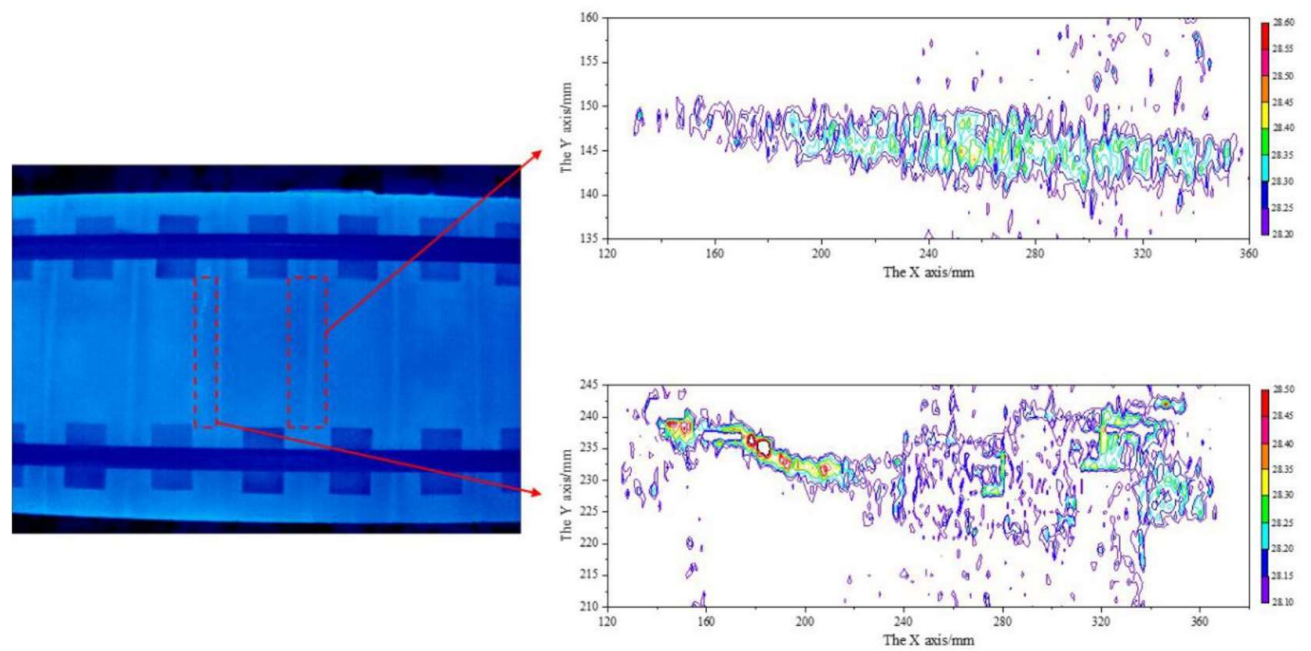

Figure 11. Temperature field isotherm at the slab surface.

Under the complex conditions of lab experiment, the adoption of IRT for crack detection requires ambient temperature no less than $20^{\circ} \mathrm{C}$, instead the $10^{\circ} \mathrm{C}$ from FE simulation. The applicability of IRT needs to be further discussed and analysed in the actual complex environment.

\subsection{Field Test}

The field test is carried out in an HSR (Sifang Ltd, Qingdao, China) section to detect the potential slab cracks using the same IRT equipment as in the laboratory test. During the test, the ambient temperature is $25.1^{\circ} \mathrm{C}$, the wind speed is $0.1 \mathrm{~m} / \mathrm{s}$, and the surface temperature of track slab is $32.78^{\circ} \mathrm{C}$.

Figure 12 shows a typical through crack on the surface of track slab. The maximum, minimum and average crack width are $0.36 \mathrm{~mm}, 0.14 \mathrm{~mm}$, and $0.27 \mathrm{~mm}$, respectively. They are measured by a portable crack detector. The temperature range of the IRT equipment is set as $15-36.5^{\circ} \mathrm{C}$, and the shooting range is set as $3 / 10$ of the track slab. Figure 13 shows the thermal image.

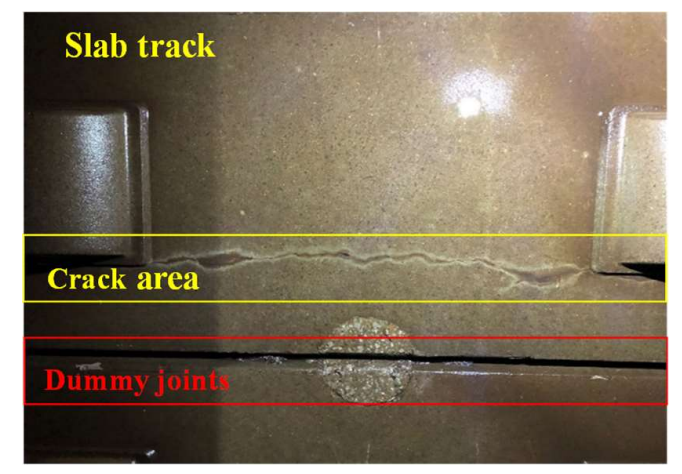

Figure 12. Field test for detection of track slab cracks. 


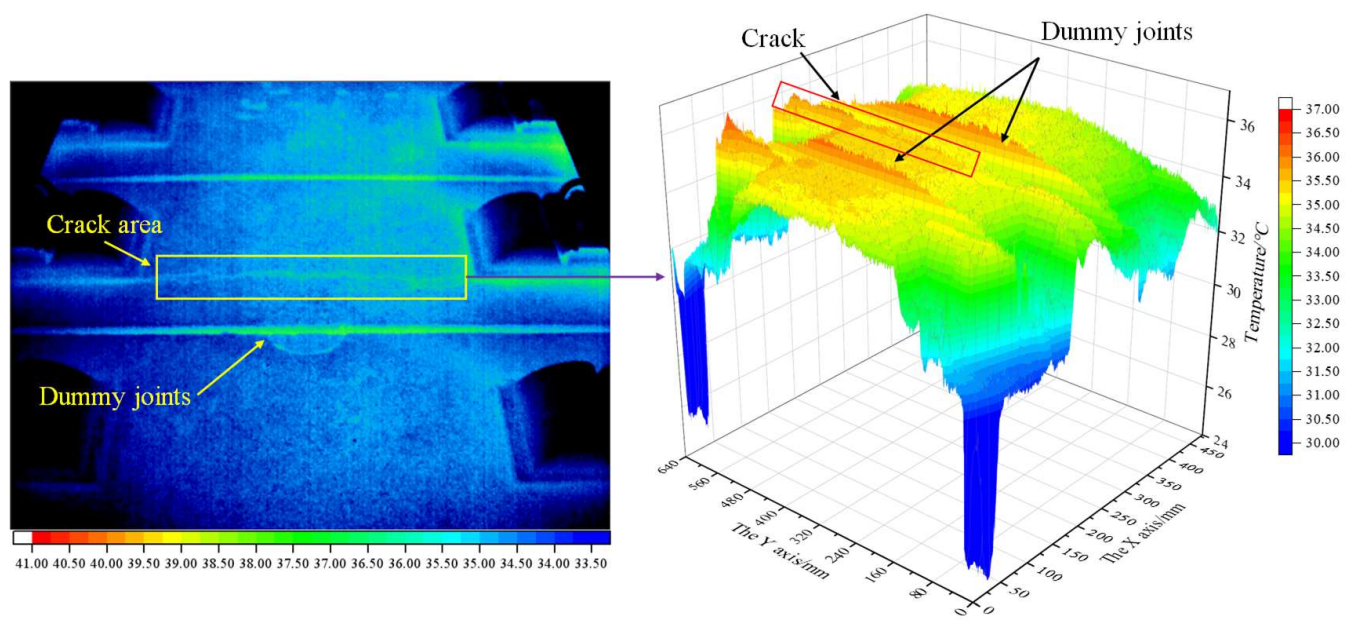

Figure 13. Typical thermography of track slab crack.

In Figure 13, different components of the track structure present different thermal images, and at dummy joints the image presents significant highlights, especially in the middle of the joint. With equal spacing, the effect of dummy joints can be easily removed before further identification of the surface cracks. In the actual crack area, the location is obvious, especially in the large-scale area, where the crack temperature and edge clearance are clear, and the characteristics are prominent.

Figure 14 shows the temperature field isotherm. Figure 15 shows that the maximum, minimum and average values of crack width are $0.36 \mathrm{~mm}, 0.14 \mathrm{~mm}$, and $0.267 \mathrm{~mm}$, respectively, which is consistent with the actual crack width. Crack area is $521.88 \mathrm{~mm}^{2}, 3.5 \%$ smaller than the actual value, which is $540 \mathrm{~mm}^{2}$. At high ambient temperature, it is feasible for the maintenance-of-way department to detect the slab cracks using IRT method.

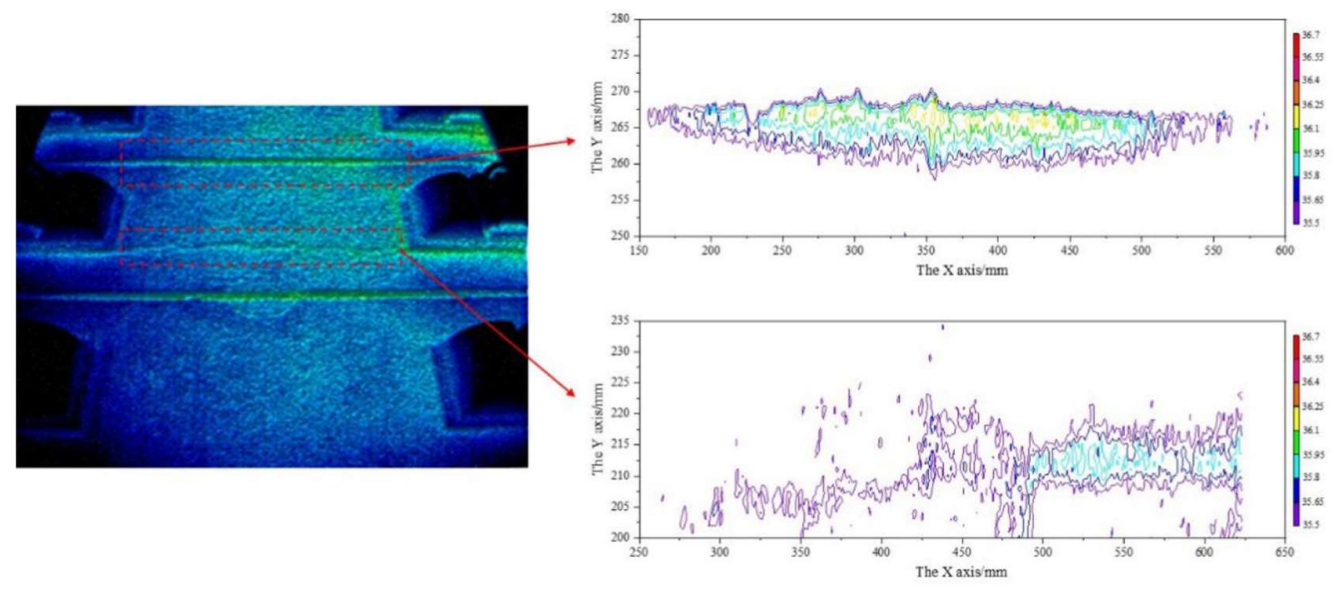

Figure 14. Temperature field isotherm of track slab crack.

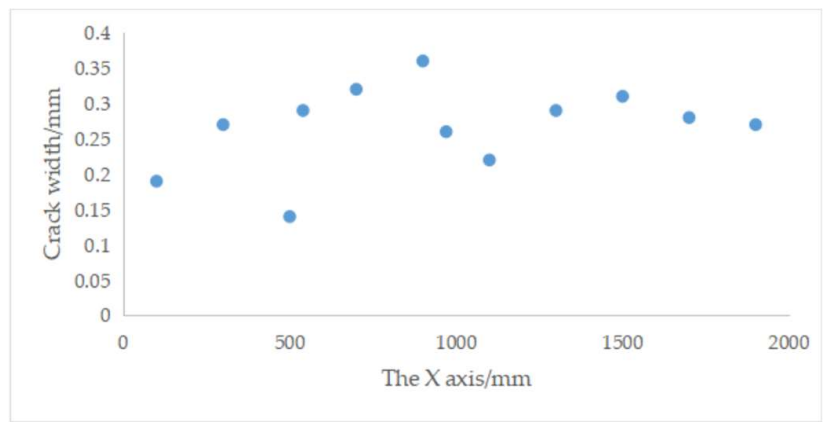

Figure 15. Results of crack width. 


\section{Conclusions}

This paper proposes an method for detecting the crack in the slab surface cracks in HSR with IRT detection. The mapping relation between the ambient temperature, crack width, and temperature difference is determined. A three-dimensional crack FE model for thermographing concrete slab track is established and is validated by the actual temperature field tests.

Through the scale-down model test in the laboratory and field test in HSR line, IRT method can effectively locate the slab surface cracks when ambient temperature is higher than $20^{\circ} \mathrm{C}$. FE parameter setting provides good reference to IRT actual application, but needs further validation in the field. Finally, a field test of IRT can detect the crack with width as small as $0.14 \mathrm{~mm}$.

Although the width of the cracks on the surface of the slab track has been successfully detected, the depth of the cracks and the threshold of the detection temperature need further studies.

Author Contributions: Conceptualization, Z.-W.L., H.-Y.L.; Data curation, Z.-W.L., X.-Z.L.; Formal analysis, Z.-W.L., X.-Z.L.; Funding acquisition, Z.-W.L., Y.-L.H.; Investigation, Z.-W.L., H.-Y.L.; Methodology, Z.-W.L., X.-Z.L.; Project administration H.-Y.L., Y.-L.H.; Resources, Z.-W.L., Y.-L.H.; Software, Z.-W.L., H.-Y.L.; Validation, Z.-W.L., X.-Z.L.; Visualization, Z.-W.L.; Roles/Writing—original draft, Z.-W.L., H.-Y.L.; Writing—review \& editing, X.-Z.L., Y.-L.Z; Supervision, Y.-L.Z. All authors have read and agreed to the published version of the manuscript.

Funding: The authors would like to appreciate the funding support by the National Natural Science Foundation of China (Grant No. 51808333 and 51978393 ).

Acknowledgments: The authors are thankful to China Railway Shanghai Group Co., Ltd., for the support of slab track.

Conflicts of Interest: The authors declare no conflict of interest. The founding sponsors had no role in the design of the study; in the collection, analyses, or interpretation of data; in the writing of the manuscript, or in the decision to publish the results.

\section{References}

1. He, Y.; Shen, J.; Li, Z.; Lu, H. Fractal Characteristics of Transverse Crack Propagation on CRTSII Type Track Slab. Math. Probl. Eng. 2019, 2019, 1-9. [CrossRef]

2. Gautier, P. Slab track: Review of existing systems and optimization potentials including very high speed. Constr. Build. Mater. 2015, 92, 9-15. [CrossRef]

3. Li, Z.; Liu, X.; He, Y. Identification of Temperature-Induced Deformation for HSR Slab Track Using Track Geometry Measurement Data. Sensors 2019, 19, 5446. [CrossRef] [PubMed]

4. Tong, F.; Gao, L.; Cai, X.; Zhong, Y.; Zhao, W.; Huang, Y. Experimental and Theoretical Determination of the Frost-Heave Cracking Law and the Crack Propagation Criterion of Slab Track with Water in the Crack. Appl. Sci. 2019, 9, 4592. [CrossRef]

5. Cao, S.; Yang, R.; Deng, S.; Li, J.; Xu, J.; Wu, M.; Zhao, H.; Liu, X. Analysis of the influence of train load characteristics on the water damage of slab tracks, Proceedings of the Institution of Mechanical Engineers. Part F J. Rail Rapid Transit 2018, 232, 2024-2038. [CrossRef]

6. Yang, X.; Shu, Y.; Zhou, S.; He, C.; Di, H. An implicit periodic nonlinear model for evaluating dynamic response of damaged slab track involving material nonlinearity of damage. Constr. Build. Mater. 2019, 197, 559-575. [CrossRef]

7. Deng, J.; Lu, Y.; Lee, V.C.S. Concrete crack detection with handwriting script interferences using faster region-based convolutional neural network. Comput.-Aided Civ. Inf. 2019, 35, 373-388. [CrossRef]

8. Ai, C.; Qiu, S.; Xu, G.; Zhang, A.; Wang, K.C.P. A Nonballasted Rail Track Slab Crack Identification Method Using a Level-Set-Based Active Contour Model. Comput.-Aided Civ. Inf. 2018, 33, 571-584. [CrossRef]

9. Xu, J.; Wang, P.; An, B.; Ma, X.; Chen, R. Damage detection of ballastless railway tracks by the impact-echo method. Proc. Inst. Civ. Eng. Transp. 2018, 171, 106-114. [CrossRef]

10. Zhou, C.S.; Wang, P.; Hu, Z.P.; Zhu, H. Numerical Simulation of Impact-Echo Method Identify the Depth of Honeycomb Damage in Unballasted Track. Appl. Mech. Mater. 2014, 584-586, 2060-2067. [CrossRef]

11. Tian, X.; Zhao, W.; Du, Y.; Wang, B. Detection of mortar defects in ballastless tracks of high-speed railway using transient elastic wave method. J. Civ. Struct. Health Monit. 2018, 8, 151-160. [CrossRef] 
12. Colla, C.; Krause, M.; Maierhofer, C.; Höhberger, H.J.; Sommer, H. Combination of NDT techniques for site investigation of non-ballasted railway tracks. NDT E Int. 2002, 35, 95-105. [CrossRef]

13. Zhu, W.; Chen, X.; Li, Z.; Meng, X.; Fan, G.; Shao, W.; Zhang, H. A SAFT Method for the Detection of Void Defect inside a Ballastless Track Structure Using Ultrasonic Array Sensors. Sensors 2019, 19, 4677. [CrossRef] [PubMed]

14. Maierhofer, C. Nondestructive Evaluation of Concrete Infrastructure with Ground Penetrating Radar. J. Mater. Civ. Eng. 2003, 15, 287-297. [CrossRef]

15. Loizos, A.; Plati, C. Ground Penetrating Radar: A Smart Sensor for the Evaluation of the Railway Trackbed. In Proceedings of the 2007 IEEE Instrumentation \& Measurement Technology Conference IMTC, Warsaw, Poland, 1-3 May 2007; pp. 1-6. [CrossRef]

16. Yang, Y.; Zhao, W. Curvelet transform-based identification of void diseases in ballastless track by ground-penetrating radar. Struct. Control Health Monit. 2019, 26, e2322. [CrossRef]

17. Wang, J.; Liu, X.; Ni, Y. A Bayesian Probabilistic Approach for Acoustic Emission-Based Rail Condition Assessment. Comput.-Aided Civ. Inf. 2018, 33, 21-34. [CrossRef]

18. Zhang, X.; Feng, N.; Wang, Y.; Shen, Y. Acoustic emission detection of rail defect based on wavelet transform and Shannon entropy. J. Sound Vib. 2015, 339, 419-432. [CrossRef]

19. Janeliukstis, R.; Clark, A.; Papaelias, M.; Kaewunruen, S. Flexural cracking-induced acoustic emission peak frequency shift in railway prestressed concrete sleepers. Eng. Struct. 2019, 178, 493-505. [CrossRef]

20. Gibert, X.; Patel, V.M.; Chellappa, R. Deep Multitask Learning for Railway Track Inspection. IEEE Trans. Intell. Transp. Syst. 2017, 18, 153-164. [CrossRef]

21. Tabatabaei, S.A.H.; Delforouzi, A.; Khan, M.H.; Wesener, T.; Grzegorzek, M. Automatic Detection of the Cracks on the Concrete Railway Sleepers. Int. J. Pattern Recogn. 2019, 33, 1955010. [CrossRef]

22. Dauti, D.; Tengattini, A.; Pont, S.D.; Toropovs, N.; Briffaut, M.; Weber, B. Some Observations on Testing Conditions of High-Temperature Experiments on Concrete: An Insight from Neutron Tomography. Transp. Porous Med. 2020, 132, 299-310. [CrossRef]

23. Dauti, D.; Tengattini, A.; Pont, S.D.; Toropovs, N.; Briffaut, M.; Weber, B. Analysis of moisture migration in concrete at high temperature through in-situ neutron tomography. Cem. Concr. Res. 2018, 111, 41-55. [CrossRef]

24. Toropovs, N.; Monte, F.L.; Wyrzykowski, M.; Weber, B.; Sahmenko, G.; Vontobel, P.; Felicetti, R.; Lura, P. Real-time measurements of temperature, pressure and moisture profiles in High-Performance Concrete exposed to high temperatures during neutron radiography imaging. Cem. Concr. Res. 2015, 68, 166-173. [CrossRef]

25. Bagavathiappan, S.; Lahiri, B.B.; Saravanan, T.; Philip, J.; Jayakumar, T. Infrared thermography for condition monitoring-A review. Infrared Phys. Technol. 2013, 60, 35-55. [CrossRef]

26. Maierhofer, C.; Arndt, R.; Röllig, M.; Rieck, C.; Walther, A.; Scheel, H.; Hillemeier, B. Application of impulse-thermography for non-destructive assessment of concrete structures. Cem. Concr. Compos. 2006, 28, 393-401. [CrossRef]

27. Sham, F.C.; Chen, N.; Long, L. Surface crack detection by flash thermography on concrete surface. Insight-Non-Destr. Test. Cond. Monit. 2008, 50, 240-243. [CrossRef]

28. Tashan, J.; Al-Mahaidi, R. Detection of cracks in concrete strengthened with CFRP systems using infra-red thermography. Compos. Part B Eng. 2014, 64, 116-125. [CrossRef]

29. Abdel-Qader, I.; Yohali, S.; Abudayyeh, O.; Yehia, S. Segmentation of thermal images for non-destructive evaluation of bridge decks. NDT E Int. 2008, 41, 395-405. [CrossRef]

30. Orbán, Z.; Gutermann, M. Assessment of masonry arch railway bridges using non-destructive in-situ testing methods. Eng. Struct. 2009, 31, 2287-2298. [CrossRef]

31. Washer, G.; Fenwick, R.; Bolleni, N. Effects of Solar Loading on Infrared Imaging of Subsurface Features in Concrete. J. Bridge Eng. 2010, 15, 384-390. [CrossRef]

32. Sirca, G.F.; Adeli, H., Jr. Infrared thermography for detecting defects in concrete structures. J. Civ. Eng. Manag. 2018, 24, 508-515. [CrossRef]

33. National Railway Administration of Science and Technology and Legal System, China. Code for Design of High Speed Railway; TB 10621-2014; China Railway Publishing House: Beijing, China, 2014. 
34. National Railway Administration of Science and Technology and Legal System, China. Maintenance Rules for Ballastless Track of High-Speed Railway (Trial); TG/GW 115-2012; China Railway Publishing House: Beijing, China, 2012.

35. Hiasa, S.; Birgul, R.; Catbas, F.N. Investigation of effective utilization of infrared thermography (IRT) through advanced finite element modeling. Constr. Build. Mater. 2017, 150, 295-309. [CrossRef]

36. Saeed, N.; Abdulrahman, Y.; Amer, S.; Omar, M.A. Experimentally validated defect depth estimation using artificial neural network in pulsed thermography. Infrared Phys. Technol. 2019, 98, 192-200. [CrossRef]

37. Liu, H.M.; Lu, H.Y.; He, Y.L.; Li, Z.W. Neural Network Based Temperature Field Mapping Model for CRTS II Type Ballastless Track. Mater. Sci. Eng. 2018, 435, 12042. [CrossRef]

38. Ramu, M.; Raja, V.P.; Thyla, P.R. Establishment of structural similitude for elastic models and validation of scaling laws. KSCE J. Civ. Eng. 2013, 17, 139-144. [CrossRef]

39. Luo, K.; Lei, X. A study of modeling experiments of the vibration behavior of elevated railway box girder. J. Vib. Control 2018, 25, 984-995. [CrossRef]

40. Peng, J.; Tian, G.Y.; Wang, L.; Zhang, Y.; Li, K.; Gao, X. Investigation into eddy current pulsed thermography for rolling contact fatigue detection and characterization. NDT E Int. 2015, 74, 72-80. [CrossRef]

Publisher's Note: MDPI stays neutral with regard to jurisdictional claims in published maps and institutional affiliations.

(C) 2020 by the authors. Licensee MDPI, Basel, Switzerland. This article is an open access article distributed under the terms and conditions of the Creative Commons Attribution (CC BY) license (http://creativecommons.org/licenses/by/4.0/). 